\title{
Determination of Fluoride in Rural Parts of Kapadwanj Region, District Kheda, Gujarat
}

\author{
S.N. PANDYA*, D.K. BHOI, H.R. DABHI and M.B. CHUAHAN \\ *Department of Chemistry, J \& J College of science,Nadiad, India. \\ *Department of Chemistry, Navjivan science college Dahod, India.
}

http://dx.doi.org/10.12944/CWE.9.1.28

(Received: February 03, 2013; Accepted: March 29, 2014)

\begin{abstract}
Analysis of well and bore well water samples for fluoride from eighteen sampling stations of Kapadwanj(Rural area) for a period of one year( 2012) during different seasons has been carried out. The analysis of different parameters namely- temperature, pHTDS and Fluoride was carried out as per standard methods. The results were compared with the values stipulated by Indian standards for drinking water. It was found that the fluoride content of all the samples obtained was well below the permissible limits.
\end{abstract}

Key words: Fluoride, Content, Kapadwanj,-- Rural Area.

\section{INTRODUCTION}

Fluoride in ground water is due to fluorspar, cryolite, fluorspatite and hydroxylapatite .Excess fluoride consumption affects plants and animals. The fluoride accumulation of ground water varies according also have an adverse effect on tooth enamel and may give rise to mild dental Fluorosis ${ }^{3}$. Longer exposure to fluoride leads to certain types of bone diseases ${ }^{4,5}$ also. Statistics reveal that fluoride poisoning is more spread than the Arsenic contamination in ground water in the country ${ }^{6}$ In view of the above, it is attempted to carry out a systematic study on fluoride contamination of ground water resources of certain rural areas of Kapadwanj,Dist-Kheda,Gujarat.

\section{MATERIALS AND METHOD}

Water samples (Bore Well \& Open Well) collected from eighteen sampling stations selected for the analysis .

All the sample bottles were stored in iceboxes till brought to the laboratory for analysis.
Solutions used for the studies were prepared from analytical grade chemicals, in double distilled water or in high purity organic solvents. All the chemicals and reagents used were of analytical grade. D.D water was used for the preparation of solutions. The analysis of parameters namely $\mathrm{PH}$,temperature and fluoride was carried out - as per the methods described7 in APHA (1995). Determination of fluoride has been carried out using Eu Tech Cyber scan 2100 instrument.

\section{RESULTS AND DISCUSSION}

The results obtained on the determination of temperature, $\mathrm{pH}$ TDS and fluoride are presented in Tables -1 to 3

\section{Temperature}

A rise in temperature of water reduces the solubility of gases and amplifies the tastes and odors. The temperature was measured using a centigrade thermometer by $110^{\circ} \mathrm{C}$ on site. The temperature of the present study ranged from 26.1 to $31.9^{\circ} \mathrm{C}$. 
$\mathrm{pH}$

High $\mathrm{pH}$ levels are undesirable since they may impart a bitter taste to the water. Furthermore, the high degree of mineralization associated with alkaline water will result in the encrustation of water pipes and water-using appliances It is known that $\mathrm{pH}$ of water (6.5 to 8.5) does not has no direct effect on health. But lower value below 5.0 produce sore taste and has higher value above 8.5 are of alkaline taste. The $\mathrm{pH}$ values of the present investigation were within the standards (6.9- 8.5)

Table 1: Analysis of Water Samples Collected in winter season

\begin{tabular}{lcccc}
\hline Name of village & Temperatures & PH & TDS (mg/L) & Fluoride(mg/L) \\
\hline Dana & 26.2 & 7.05 & 840 & 0.5 \\
Shankarpura & 26.1 & 7.2 & 250 & 0.3 \\
Abaliyara & 26.5 & 6.95 & 210 & 0.2 \\
Anklai & 27.2 & 6.90 & 440 & 0.5 \\
Narana muvada & 26.3 & 7.20 & 185 & 0.8 \\
Vasana & 26.2 & 7.25 & 410 & 0.9 \\
Charania & 27.1 & 7.40 & 240 & 0.78 \\
Bhagavanji na muvada & 26.2 & 7.05 & 380 & 0.5 \\
Torana & 27.1 & 7.0 & 980 & 0.5 \\
Antroli & 26.5 & 7.3 & 480 & 0.46 \\
Antarsumba & 27.0 & 6.92 & 710 & 0.5 \\
Betawada & 26.2 & 7.25 & 1250 & 1.0 \\
Navagam & 26.4 & 6.90 & 490 & 0.5 \\
Danadara & 26.7 & 7.8 & 670 & 1.2 \\
Motizer & 27.5 & 7.05 & 450 & 0.78 \\
Zanda & 26.9 & 6.90 & 460 & 0.5 \\
Thavad & 27.2 & 7.82 & 970 & 0.81 \\
Lalpur & 26.7 & 8.05 & 370 & 0.54 \\
\hline
\end{tabular}

Table 2: Analysis Samples Collected in rainy season of Water

\begin{tabular}{lcccc}
\hline Name of village & Temperatures & PH & TDS (mg/L) & Fluoride(mg/L) \\
\hline Dana & 31.3 & 7.1 & 640 & 0.5 \\
Shankarpura & 31.7 & 7.2 & 250 & 0.3 \\
Abaliyara & 30.5 & 6.95 & 210 & 0.2 \\
Anklai & 31.2 & 6.90 & 450 & 0.5 \\
Narana muvada & 29.4 & 7.20 & 185 & 0.8 \\
Vasana & 29.8 & 7.0 & 410 & 0.9 \\
Charania & 29.7 & 7.5 & 300 & 0.78 \\
Bhagavanji na muvada & 30.7 & 6.9 & 380 & 0.5 \\
Torana & 29.7 & 7.0 & 850 & 0.5 \\
Antroli & 30.4 & 7.3 & 350 & 0.46 \\
Antarsumba & 30.8 & 6.92 & 710 & 0.5 \\
Betawada & 31.9 & 7.3 & 1300 & 1.0 \\
Navagam & 29.5 & 6.9 & 490 & 0.5 \\
Danadara & 29.6 & 7.8 & 650 & 1.2 \\
Motizer & 29.5 & 7.05 & 450 & 0.78 \\
Zanda & 31.9 & 6.90 & 460 & 0.5 \\
Thavad & 31.2 & 7.82 & 850 & 0.81 \\
Lalpur & 29.7 & 8.1 & 500 & 0.54 \\
\hline
\end{tabular}


Table 3: Analysis of Water Samples Collected in Summer season

\begin{tabular}{lcccc}
\hline Name of village & Temperatures & PH & TDS $(\mathbf{m g} / \mathbf{L})$ & Fluoride(mg/L) \\
\hline Dana & 31.8 & 7.0 & 550 & 0.3 \\
Shankarpura & 31.4 & 7.2 & 250 & 0.2 \\
Abaliyara & 30.5 & 6.95 & 260 & 0.5 \\
Anklai & 31.2 & 6.90 & 440 & 0.8 \\
Narana muvada & 29.6 & 7.4 & 185 & 0.9 \\
Vasana & 29.8 & 7.3 & 410 & 0.78 \\
Charania & 29.7 & 6.9 & 240 & 0.78 \\
Bhagavanji na muvada & 30.7 & 7.1 & 380 & 0.5 \\
Torana & 29.7 & 7.0 & 950 & 0.46 \\
Antroli & 30.4 & 7.3 & 480 & 0.5 \\
Antarsumba & 30.8 & 6.92 & 710 & 1.0 \\
Betawada & 31.9 & 7.25 & 1000 & 0.5 \\
Navagam & 29.5 & 6.90 & 490 & 1.2 \\
Danadara & 29.7 & 7.8 & 670 & 0.78 \\
Motizer & 29.5 & 7.0 & 450 & 0.5 \\
Zanda & 31.9 & 6.90 & 600 & 1.2 \\
Thavad & 31.2 & 7.82 & 970 & 0.5 \\
Lalpur & 29.7 & 7.9 & 450 & 0.78 \\
\hline
\end{tabular}

TDS

A large number of solids are found dissolved in natural water the common ones are carbonates,bicarbonates, chloride,sulphate,phosphate ,ironetc,.In other words TDS is sum of the cations and anions concentration. A high contents of dissolve solids elevates the density of water,influences solubility of gases(like oxygen) reduces utility of water for drinking irrigation and industrial purpose. In the present study TDS ranged from $210 \mathrm{mg} / \mathrm{L}$ to $1300 \mathrm{mg} / \mathrm{L}$. According to WHO and Indian standards TDS values should be less than $500 \mathrm{mg} / \mathrm{L}$ for drinking water.

\section{Fluoride}

Out of eighteen sampling stations studied, low fluoride concentration is noticed in the All samples. $1.2 \mathrm{mg} / \mathrm{lit}$ as prescribed by Indian standards for drinking water quality ${ }^{8}$.

\section{CONCLUSIONS}

It can be concluded form the above study that fluoride content in all areas was found below the permissible levels than required. Hence people in those areas should consume protected water containing fluoride within the required levels .

\section{AKNOWLEDGEMENTS}

The Authors are thankful to the UGC for financial assistance in the form of Minor Research Project [F No. 47-511-2008 [ WRO] Date : 2-2-2009] The Authors are also thankful to "The Nadiad Education Society, Nadiad and "The Principal of $\mathrm{J}$ \& J College of Science," Nadiad for providing necessary facilities. 


\section{REFERENCES}

1. S.Meenakshi and R.C.Maheshwari , J.Hard.Mater., 137: 456 (2006),

2. D.S Bendale., G.R Chaudhari and G.K. Gupta,. An evaluation of ground water quality in Awal taluk, Jalgaon Dist., A Physicochemical and metallic study, Asian J. Chem. \& Env. 3(1): 65-71(2010).

3. Sai Srikanth, Symposium Fluorosis Hyderabad Proceedings, 407-409 (1974).

4. L Jarup, British Medical Bulletin, 68, 167182 (2003).

5. DHHS (Department of Health and Human
Services), Review of Fluoride benefits and risks. Department of Health and Human Services, Washington, D.C. (1999).

6. APHA,.Standard methods for the examination of water and waste water, 20thedn Washington, D.C (USA), (1998).

7. World Health organization, Guide lines for drinking water quality, 3rd edn., WHO, Geneva, (2006).

8. A.I.Vogel, Text Book of Quantitative,Inorganic Analysis, $4^{\text {th }}$ Edn,ELBS, London (1978) 